\title{
Diabetes and Prior Coronary Heart Disease are Not Necessarily Risk Equivalent for Future Coronary Heart Disease Events
}

\author{
Jamal S. Rana, MD, $P h D^{1,2,3,5}$, Jennifer Y. Liu, $\mathrm{MPH}^{3}$, Howard H. Moffet, $\mathrm{MPH}^{3}$, Marc Jaffe, $\mathrm{MD}^{4}$, and \\ Andrew J. Karter, $P h D^{3}$ \\ 'Division of Cardiology, Kaiser Permanente Northern California, Oakland, CA, USA; ${ }^{2}$ Department of Medicine, University of California San Francisco, \\ San Francisco, CA, USA; ${ }^{3}$ Division of Research, Kaiser Permanente Northern California, Oakland, CA, USA; ${ }^{4}$ Division of Endocrinology, Kaiser \\ Permanente Medical Center, South San Francisco, CA, USA; ${ }^{5}$ Division of Cardiology, Kaiser Permanente Oakland Medical Center, Oakland, CA, \\ USA.
}

BACKGROUND: For more than a decade, the presence of diabetes has been considered a coronary heart disease (CHD) "risk equivalent".

OBJECTIVE: The objective of this study was to revisit the concept of risk equivalence by comparing the risk of subsequent CHD events among individuals with or without history of diabetes or CHD in a large contemporary realworld cohort over a period of 10 years (2002 to 2011).

DESIGN: Population-based prospective cohort analysis.

PARTICIPANTS: We studied a cohort of 1,586,061 adult members (ages 30-90 years) of Kaiser Permanente Northern California, an integrated health care delivery system.

MAIN MEASUREMENTS: We calculated hazard ratios (HRs) from Cox proportional hazard models for CHD among four fixed cohorts, defined by prevalent (baseline) risk group: no history of diabetes or CHD (None), prior CHD alone (CHD), diabetes alone (DM), and diabetes and prior CHD (DM+CHD).

KEY RESULTS: We observed 80,012 new CHD events over the follow-up period $(\sim 10,980,800$ person-years $)$. After multivariable adjustment, the HRs (reference: None) for new CHD events were as follows: CHD alone, 2.8 (95 \% CI, 2.7-2.85); DM alone 1.7 (95\% CI, 1.661.74); DM+CHD, 3.9 (95\% CI, 3.8-4.0). Individuals with diabetes alone had significantly lower risk of CHD across all age and sex strata compared to those with CHD alone (12.2 versus 22.5 per 1000 person-years). The risk of future CHD for patients with a history of either DM or CHD was similar only among those with diabetes of long duration ( $\geq 10$ years).

CONCLUSIONS: Not all individuals with diabetes should be unconditionally assumed to be a risk equivalent of those with prior CHD.

KEY WORDS: coronary heart disease; diabetes; epidemiology.

J Gen Intern Med 31(4):387-93

DOI: $10.1007 / \mathrm{s} 11606-015-3556-3$

(c) Society of General Internal Medicine 2015

Received June 22, 2015

Revised September 18, 2015

Accepted November 24, 2015

Published online December 14, 2015

\section{INTRODUCTION}

The prevalence and burden of diabetes mellitus remains high. ${ }^{1}$ After Haffner et al. ${ }^{2}$ reported that adults with diabetes had the same risk for future myocardial infarction (MI) as adults with previous MI and without diabetes, the Adult Treatment Panel (ATP) III guidelines in 2001 recommended that all individuals with diabetes be considered as "Coronary heart disease (CHD) risk equivalent". ${ }^{3}$ However, the latest 2013 ACC/AHA assessment of risk guidelines considers diabetes as only one of the many variables in its risk assessment equation. ${ }^{4}$

The assertion that all patients with diabetes are CHD equivalent has been controversial. ${ }^{5,6}$ Existing evidence is based on relatively small studies with various limitations. Some studies were limited to a single gender, ${ }^{7-9}$ while others were based on self-reported diagnosis of diabetes. ${ }^{10,11}$ Some lacked the ability to adjust for important confounding risk factors. ${ }^{12,13}$ Most of the studies have comprised cohorts from the $1990 \mathrm{~s},{ }^{5}$ and only a few studies have been able to evaluate the impact of the duration of diabetes. ${ }^{7,8,14}$ There is also a paucity of data among relatively young (30-40 years) patients with diabetes. For all these reasons, updated evidence from a contemporary population is needed to inform our understanding of CHD risk in diabetes patients.

We compared the risk of a CHD event among individuals with and without a history of diabetes or CHD among a large $(n=1,586,061)$, ethnically diverse, contemporary real-world cohort of patients in usual care over a period of 10 years (January 1, 2002, through December 31, 2011).

\section{METHODS}

Kaiser Permanente Northern California (KPNC) is a large integrated health care delivery system caring for more than three million persons who are broadly representative of the service area. ${ }^{15,16}$ As of January 1, 2002 (baseline), there were $1,843,856$ active KPNC members, ages 30 to 90 years. We excluded individuals not continuously enrolled during the 12 months prior to baseline $(n=257,795)$ in order to avoid misclassification of new enrollees with pre-existing CHD. The final study population included 1,586,061 subjects. Our outcome of interest was the rate of new CHD events during 2002- 
2011 across four exposure categories defined by prevalent CHD or prevalent diabetes (as of January 1, 2002, baseline): 1) no diabetes or CHD ("None"); 2) prior CHD alone ("CHD"); 3) Diabetes alone ("DM") 4) Diabetes and CHD (“CHD+DM").

\section{Identification of Diabetes}

Patients with prevalent diabetes were identified in the year prior to baseline based on a well-validated algorithm ${ }^{17}$ to build a cumulative list of patients with this chronic disease. Diabetes identification was based on any of the following: 1) inpatient diagnosis (principal diagnosis of ICD-9: 250) or outpatient diagnosis (two or more diagnoses with ICD-9: 250; excludes diagnoses collected in the emergency room or optometry or ophthalmology departments); 2) two abnormal outpatient laboratory results (fasting glucose $\geq 126 \mathrm{mg} / \mathrm{dL}$; random or postchallenge [ $75 \mathrm{~g}$ ] glucose $\geq 200 \mathrm{mg} / \mathrm{dL} ; \mathrm{HbA} 1 \mathrm{c} \geq 6.5 \%$ ), tested on separate days within a 3-year period; or 3) pharmacy utilization for insulin or certain oral anti-hyperglycemic medications. Newly identified diabetes cases were excluded if they were based on a diagnosis of gestational diabetes (ICD-9: 648.8), identified due to the use of insulin sensitizers thiazolidinedione or metformin for conditions other than diabetes (e.g., pre-diabetes or polycystic ovary syndrome), or included due to a single criterion without subsequent diabetes-related utilization within a 2-year period. Of note, diabetes cases are ascertained on an ongoing basis, and the Kaiser Diabetes Registry maintains a cumulative record of existing and each new DM diagnosis. DM remissions are dropped from the registry; however, remissions are very rare. ${ }^{18}$

\section{Identification of Coronary Heart Disease}

Patients with prevalent $\mathrm{CHD}$ at baseline were identified by the presence of any (non-fatal) CHD diagnosis during the 5 years before baseline (January 1, 2002); incident CHD events were identified during the 10 years of follow-up from baseline via hospitalization and medical records. Both prevalent and incident CHD identification was based on inpatient primary diagnosis or procedure records, as follows: fatal and non-fatal MI (ICD-9 diagnosis codes: 410-414, 429.2; ICD-10 diagnosis codes: I20-I25), percutaneous coronary intervention (PCI; ICD-9 procedure codes: $36.01,36.02,36.05,36.06,36.07$, 36.09, 00.66 or CPT 4 codes: 92980, 92981, 92982, 92984, 92995, 92996); and coronary artery bypass surgery (CABG; ICD-9 procedure codes: $36.03,36.1 \times$ or CTP 4 codes: 33533 , $33534,33535,33536,33572,33510,33511,33512$, 33513, $33514,33516,33517,33518,33519,33521,33522$, 33523, 33530). Fatal events were also identified through the California mortality file.

\section{Patient Characteristics}

Age, sex, and race/ethnicity were ascertained from selfreported demographic data collected at clinic visits, during health plan enrollment, from member surveys, or on hospitalization intake forms. Relevant ambulatory laboratory values (e.g., total cholesterol [TC], low-density lipoprotein cholesterol [LDL-C], triglycerides [TG], high-density lipoprotein cholesterol [HDL-C], and $\mathrm{HbAlc}$ ), hypertension (diagnosis of hypertension or use of anti-hypertensive medications ), smoking status (never, ever, current), and medication use were ascertained from KPNC databases.

\section{Statistical Analysis}

Categorical variables are presented as percentages and continuous variables as mean and standard deviation. We calculated crude and age-adjusted overall and gender-specific rates of CHD (number of events per 1,000 person-years [p-y]) for each exposure category. We specified Cox proportional hazard regression models to estimate hazard ratios as a measure of the difference in rates of CHD across the four categories. We specified the following series of multivariable adjusted models: Model 1: 10-year age categories (30-39, 40-49, 5059, 60-69, 70-79 and 80-90 years), sex and race/ethnicity; Model 2: model 1 plus ever smoking and hypertension; Model 3: model 2 plus presence of dyslipidemia (TC $\geq 200 \mathrm{mg} / \mathrm{dl}$ or LDL-C $\geq 130 \mathrm{mg} / \mathrm{dl}$ or $\mathrm{TG} \geq 150 \mathrm{mg} / \mathrm{dl}$ or HDL [Females $<50 \mathrm{mg} / \mathrm{dl}$, Males $<40 \mathrm{mg} / \mathrm{dl}]$ ); Model 4: model 3 plus statin use; and Model 5: a saturated model that adjusted for all the above variables. We believe that correlation between dyslipidemia and statin treatment is not a concern in this particular study design, as collinearity between an exposure of interest and a confounder is a concern when estimating effect sizes for a given exposure, but confounder-confounder collinearity has minimal impact on adjusted models given that we are not trying to estimate the effect of either confounder.

Ten-year Kaplan-Meier Survival curves with new CHD event as outcome were compared across the four categories. We also calculated CHD rates for each 10-year age category for men and women separately.

All analyses were performed with SAS version 9.1 software (SAS Institute, Cary, NC, USA), and associations were considered statistically significant at the 0.05 level.

\section{RESULTS}

Among the 1,586,061 adults at baseline, 1,405,105 (88.6\%) had no prevalent diabetes or CHD, 42,449 (2.7\%) had prior CHD alone, 118,952 (7.5\%) had diabetes alone, and 19,555 $(1.2 \%)$ had both diabetes and CHD. Individuals with a history of CHD, irrespective of diabetes status, were more likely to be male, older, and statin users than those without prevalent CHD (Table 1).

Individuals with diabetes and CHD at baseline were more likely to have had diabetes longer than 10 years compared to those with diabetes alone (27.2\% and $12.7 \%$, respectively). The mean $\mathrm{HbA} 1 \mathrm{C}$ was lower among patients with diabetes and $\mathrm{CHD}$ versus diabetes alone ( $7.7 \pm 1.7$ versus $8.0 \pm 1.9$; 
Table 1 Baseline Characteristics of Population According to Baseline Diabetes and Prior Coronary Heart Disease (CHD) Status

\begin{tabular}{|c|c|c|c|c|}
\hline \multirow[t]{2}{*}{ Characteristic } & \multicolumn{2}{|c|}{$\begin{array}{l}\text { Individuals without diabetes } \\
N=1,447,554\end{array}$} & \multicolumn{2}{|c|}{$\begin{array}{l}\text { Individuals with diabetes } \\
N=138,507\end{array}$} \\
\hline & No Prior CHD & Prior CHD & No Prior CHD & Prior CHD \\
\hline No. of individuals & $1,405,105$ & 42,449 & 118,952 & 19,555 \\
\hline Male sex (\%) & 46.3 & 64.0 & 52.0 & 62.5 \\
\hline Age, years (mean $\pm S D)$ & $50.8 \pm 13.8$ & $69.4 \pm 11.5$ & $59.6 \pm 12.6$ & $67.9 \pm 10.4$ \\
\hline \multicolumn{5}{|l|}{ Age group $(\%)$} \\
\hline $30-40$ & 24.2 & 0.7 & 5.8 & 0.4 \\
\hline$>40-50$ & 27.6 & 5.0 & 16.6 & 4.3 \\
\hline$>50-60$ & 22.9 & 15.8 & 27.9 & 17.4 \\
\hline$>60-70$ & 13.2 & 24.0 & 25.5 & 30.2 \\
\hline$>70-80$ & 8.6 & 33.1 & 18.6 & 34.3 \\
\hline$>80-89$ & 3.4 & 21.3 & 5.6 & 13.4 \\
\hline \multicolumn{5}{|l|}{ Ethnic group (\%) } \\
\hline White & 62.4 & 75.5 & 50 & 62.2 \\
\hline Black & 7.9 & 6.6 & 12.4 & 10.2 \\
\hline Hispanic & 12.0 & 5.6 & 15.4 & 10.2 \\
\hline Asian & 13.6 & 6.8 & 15.8 & 10.1 \\
\hline Other & 4.1 & 5.5 & 5.5 & 7.3 \\
\hline \multicolumn{5}{|l|}{ Lipids (mg/dl) } \\
\hline Total cholesterol & $215.2 \pm 40.6$ & $195.9 \pm 40.4$ & $207.8 \pm 44.6$ & $191.4 \pm 44.4$ \\
\hline LDL cholesterol & $133.5 \pm 34.9$ & $113 \pm 32.6$ & $121 \pm 34.8$ & $106.7 \pm 33.3$ \\
\hline HDL cholesterol & $53.6 \pm 15.3$ & $48.6 \pm 14.3$ & $46.1 \pm 12.6$ & $43.1 \pm 12.5$ \\
\hline Triglycerides & $160 \pm 101$ & $167 \pm 100$ & $202.7 \pm 130$ & $206.7 \pm 131$ \\
\hline Total Cholesterol $\geq 200 \mathrm{mg} / \mathrm{dl}(\%)$ & 64.1 & 40.8 & 54.3 & 35.9 \\
\hline LDL Cholesterol $\geq 130 \mathrm{mg} / \mathrm{dl}(\%)$ & 52.3 & 25.2 & 36.2 & 20.2 \\
\hline HDL Cholesterol (Females<50 mg/dl, Males<40 mg/dl) (\%) & 29.2 & 37 & 49.8 & 57 \\
\hline Triglycerides $\geq 150 \mathrm{mg} / \mathrm{dl}(\%)$ & 42.6 & 45.3 & 58.7 & 60.1 \\
\hline Statin use $(\%)$ & 5.5 & 58.9 & 31 & 66.4 \\
\hline \multicolumn{5}{|l|}{ Smoking history (\%) } \\
\hline Never & 63 & 42.4 & 57 & 40.7 \\
\hline Ever & 37 & 57.6 & 43 & 59.3 \\
\hline Current & 21.9 & 23.7 & 20.5 & 22.7 \\
\hline Hypertension history (\%) & 22.7 & 85.2 & 69.9 & 93.9 \\
\hline Duration of diabetes & & & $5.1 \pm 3.9$ & $7.1 \pm 4.5$ \\
\hline \multicolumn{5}{|l|}{ Duration groups $(\%)$} \\
\hline $0-4$ years & & & 55.9 & 36.8 \\
\hline $5-9$ years & & & 31.5 & 36.0 \\
\hline$>10$ years & & & 12.7 & 27.2 \\
\hline Hb A1C (\%) & & & $8.0 \pm 1.9$ & $7.7 \pm 1.7$ \\
\hline $\mathrm{Hb}$ A $1 \mathrm{C} \geq 9 \%,(\%)$ & & & 23.1 & 18.9 \\
\hline Insulin therapy (\%) & & & 17.8 & 31.7 \\
\hline Oral antihypoglycemic therapy $(\%)$ & & & 65.1 & 63.2 \\
\hline
\end{tabular}

Plus-minus values are means $\pm S D$

$p<0.01)$, although insulin use was much higher $(31.7 \%$ versus $17.8 \% ; p<0.01$ ).

We observed 80,012 new CHD events during the 10,980,800 p-y follow-up (median follow-up of $9.9 \pm 3.6$ years). The ageadjusted CHD rate was lowest (4.8 per 1000 p-y) among individuals with no CHD or diabetes, and highest among those with prevalent diabetes and CHD (37.3 per 1000 p-y) (Table 2). Of note, the age-adjusted CHD rate per $1000 \mathrm{p}$-y for individuals with prevalent CHD alone was 22.5 per 1000 py, almost twice that among those with prevalent diabetes alone (12.2 per 1000 p-y). The patterns were similar for men and women.

After adjusting for age, sex, and race/ethnicity (model 1), the hazard ratios (reference: no diabetes or CHD) from the 10-year Cox proportional model of new CHD events were 4.0 (95\% CI, 3.9-4.1), 2.4 (95\% CI, 2.4-2.5), and 6.8 (95\% CI, 6.6-6.9) among individuals with prior CHD alone, with diabetes alone, and with both diabetes and CHD, respectively. After additional adjustment for smoking and hypertension (model 2), these same three HRs were 3.1 (95\% CI, 3.0-3.2), 2.0 (95\% CI, 1.9-2.1), and 4.8 (95\% CI, 4.7-4.9), respectively. In the final model 5, these HRs were slightly attenuated to 2.8 (95\% CI, 2.7-2.85), 1.7 (95\% CI, 1.66-1.74), and 3.9 (95\% CI, 3.8-4.0), respectively (Table 2). Furthermore, in model 5 , changing the variable of age from categorical to continuous, the HRs remained similar: 2.71 (95 \% CI 2.6-2.8), 1.7 (95\% CI, 1.66-1.7), and 3.9 (95\% CI, 3.75-4.0), respectively. Thus, despite adjustment for a wide range of known risk factors across five models, we observed modest changes in point estimates, indicating some confounding. However, the pattern of between-group ranking remained unchanged by adjustment: the CHD+DM group was always at highest risk, followed by CHD, then DM, and finally no CHD or DM.

In addition, we calculated the HR for future CHD among those with diabetes alone compared to those with prior CHD 
Table 2 Rates and Risk for Coronary Heart Disease on 10 year follow up by Diabetes and CHD Status

\begin{tabular}{|c|c|c|c|c|}
\hline Variable & No Diabetes or CHD & $\begin{array}{l}\text { Prior CHD } \\
\text { alone }\end{array}$ & $\begin{array}{l}\text { Diabetes } \\
\text { alone }\end{array}$ & $\begin{array}{l}\text { Diabetes and } \\
\text { CHD }\end{array}$ \\
\hline No. of individuals & $1,405,105$ & 42,449 & 118,952 & 19,555 \\
\hline Person years & $9,843,506$ & 238,276 & 805,152 & 93,866 \\
\hline Average follow-up time (person-years) & 7.01 & 5.6 & 6.7 & 4.8 \\
\hline No. of cases & 47,042 & 11,648 & 14,250 & 7,072 \\
\hline Incidence rate, $\%$ & 3.3 & 27.4 & 12 & 36.2 \\
\hline No. $/ 1000$ person years & 4.8 & 48.9 & 17.7 & 75.3 \\
\hline \multicolumn{5}{|l|}{ Age-adjusted No. $/ 1000$ person years $(95 \% \mathrm{CI})$} \\
\hline Overall & $\begin{array}{l}4.9 \\
(4.8-4.96)\end{array}$ & $\begin{array}{l}22.5 \\
(22.0-22.98)\end{array}$ & $\begin{array}{l}12.2 \\
(12.02-12.49)\end{array}$ & $\begin{array}{l}37.3 \\
(36.35-38.26)\end{array}$ \\
\hline Women & $\begin{array}{l}3.0 \\
(2.98-3.11)\end{array}$ & $\begin{array}{l}15.5 \\
(14.95-16.12)\end{array}$ & $\begin{array}{l}8.8 \\
(8.58-9.14)\end{array}$ & $\begin{array}{l}28.9 \\
(27.69-30.23)\end{array}$ \\
\hline Men & $\begin{array}{l}7.2 \\
(7.11-7.32)\end{array}$ & $\begin{array}{l}26.1 \\
(25.46-26.79)\end{array}$ & $\begin{array}{l}15.2 \\
(14.8-15.53)\end{array}$ & $\begin{array}{l}41.0 \\
(39.71-42.31)\end{array}$ \\
\hline \multicolumn{5}{|l|}{10 year Hazard Ratio $(95 \% \mathrm{CI})$} \\
\hline Unadjusted & Reference & $\begin{array}{l}10.2 \\
(9.9-10.4)\end{array}$ & $\begin{array}{l}3.7 \\
(3.6-3.8)\end{array}$ & $\begin{array}{l}15.6 \\
(15.2-16.0)\end{array}$ \\
\hline Model 1 (Adjusted for age by 10 years, sex, ethnicity) & Reference & $\begin{array}{l}4.0 \\
(3.9-4.1)\end{array}$ & $\begin{array}{l}2.4 \\
(2.4-2.5)\end{array}$ & $\begin{array}{l}6.8 \\
(6.6-6.9)\end{array}$ \\
\hline Model 2 (Model 1+ smoking status, history of hypertension) & Reference & $\begin{array}{l}3.1 \\
(3.0-3.2)\end{array}$ & $\begin{array}{l}2.0 \\
(1.9-2.1)\end{array}$ & $\begin{array}{l}4.8 \\
(4.7-4.9)\end{array}$ \\
\hline Model 3 (Model 2+dyslipidemia*) & Reference & $\begin{array}{l}3.88 \\
(3.8-4.0)\end{array}$ & $\begin{array}{l}2.10 \\
(2.06-2.15)\end{array}$ & $\begin{array}{l}6.03 \\
(5.9-6.2)\end{array}$ \\
\hline Model 4 (Model 3+Statin use) & Reference & $\begin{array}{l}3.28 \\
(3.20-3.35)\end{array}$ & $\begin{array}{l}2.22 \\
(2.18-2.27)\end{array}$ & $\begin{array}{l}5.43 \\
(5.29-5.59)\end{array}$ \\
\hline Model 5 (Adjusted for all variables in models $1-4$ ) & Reference & $\begin{array}{l}2.76 \\
(2.69-2.85)\end{array}$ & $\begin{array}{l}1.70 \\
(1.66-1.74)\end{array}$ & $\begin{array}{l}3.91 \\
(3.78-4.05)\end{array}$ \\
\hline
\end{tabular}

*TC $\geq 200 \mathrm{mg} / \mathrm{dl}$ or $L D L-C \geq 130 \mathrm{mg} / \mathrm{dl}$ or $T G \geq 150 \mathrm{mg} / \mathrm{dl}$ or HDL (Females $<50 \mathrm{mg} / \mathrm{dl}$, Males $<40 \mathrm{mg} / \mathrm{dl}$

as a reference group, and found an HR of 0.61 ( $95 \% \mathrm{CI}$, $0.60-0.63$ ) for model 1 , which remained unchanged for fully adjusted model 5, at HR 0.61 (95\% CI, 0.60-0.63).

Crude Kaplan-Meier estimates of the proportion of individuals with $\mathrm{CHD}$ events during follow-up in the four categories (Fig. 1) further demonstrated that risk of CHD increased in a stepwise fashion from no diabetes or CHD (lowest risk), to diabetes only, prior CHD only, and finally to presence of both diabetes and CHD (highest risk). We also evaluated CHD rates (per 1000 p-y) stratified by sex and age in all four exposure categories (Fig. 2). Regardless of age category, the rates reflected the same pattern of risk based on prevalent disease. Men with diabetes alone at ages 40-49 had 9 CHD events per
1000 p-y (0.9 \% annually), and women with diabetes alone had 6.6 CHD events per 1000 p-y ( $\sim 0.7 \%$ annually) at age group 40-49 years. Rates were even lower for the population $<40$ years of age. While men generally had higher CHD rates, the relative patterns across the four categories were similar for men and women (Fig. 2).

We then explored the role of duration of diabetes and risk of CHD. Among individuals with diabetes alone, the fully adjusted (model 5) risk of CHD increased incrementally with longer diabetes duration (Fig. 3). Among individuals with diabetes for at least 10 years at baseline, the risk of CHD was similar to that observed in individuals with prior CHD (HR 2.7, $95 \%$ CI 2.62.8 versus HR 2.5, $95 \%$ CI 2.4-2.6, respectively).

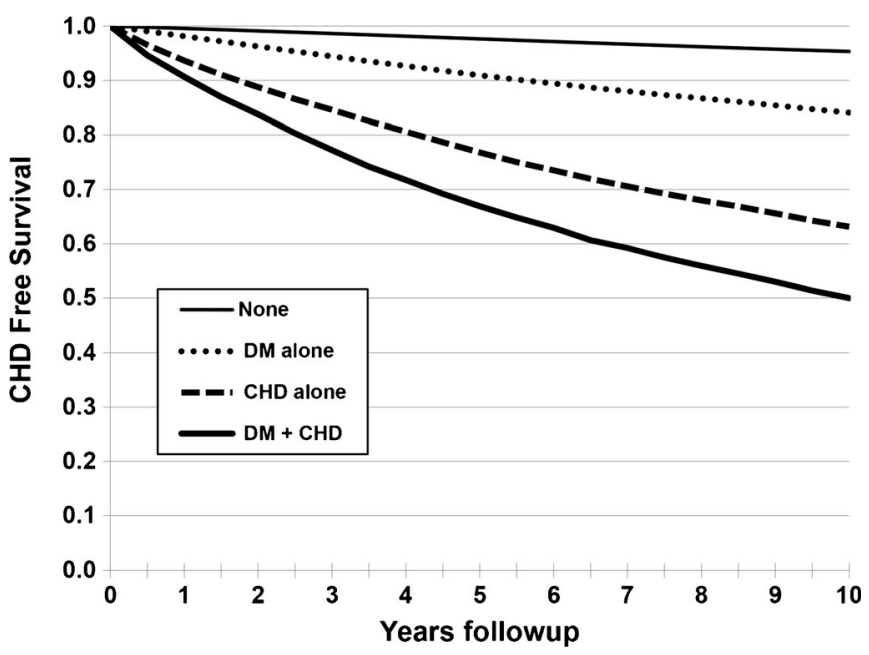

Figure 1 Kaplan-Meier estimates of coronary heart disease defined by baseline history of diabetes or CHD among four cohorts. The four cohorts are defined as: no diabetes or CHD (None); prior CHD alone (CHD); diabetes alone (DM); diabetes and CHD (DM+CHD), from $2002-2011$. 

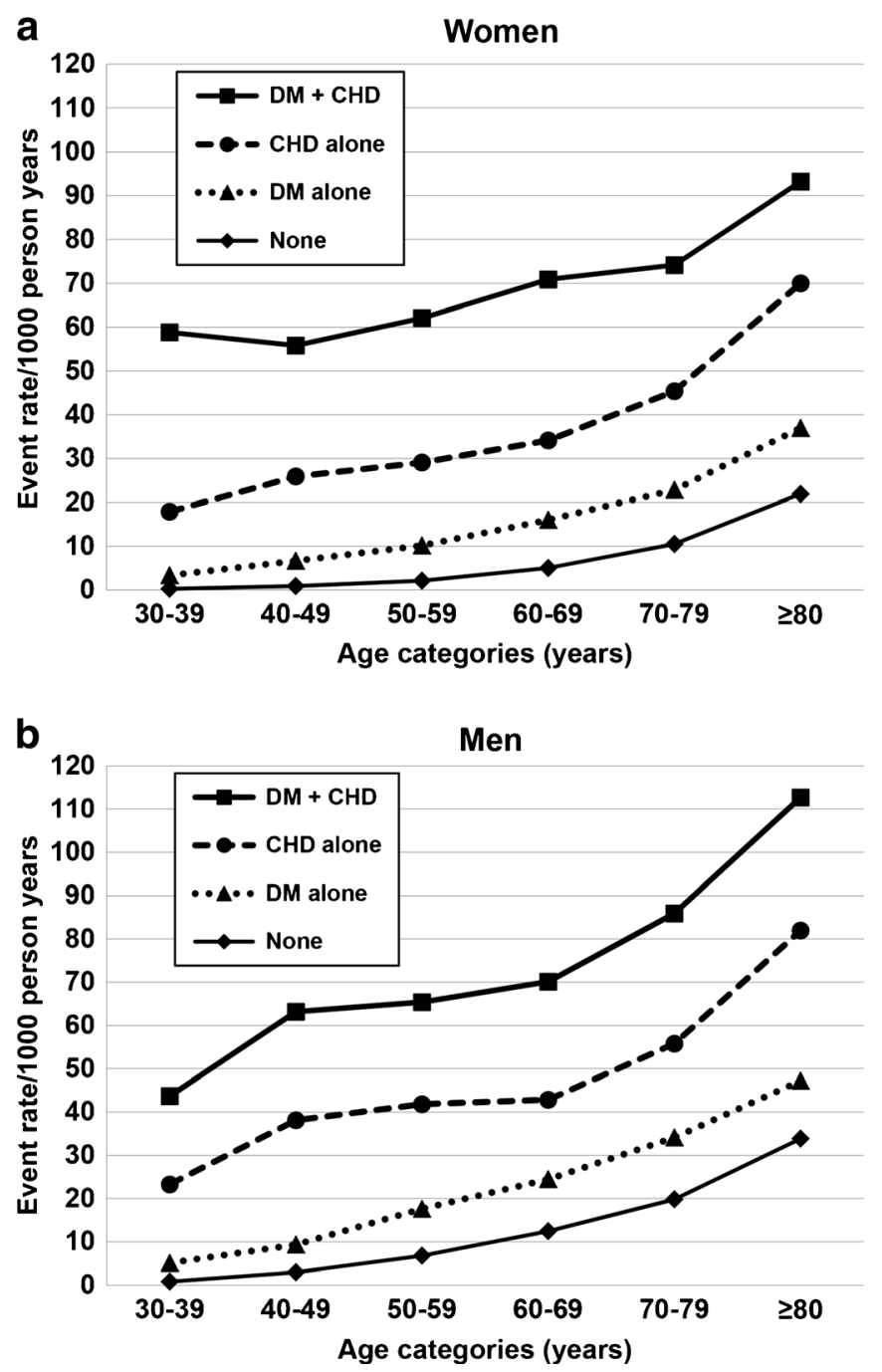

Figure 2 Coronary heart disease rates stratified by sex and age in four cohorts by history of diabetes or CHD. Coronary heart disease rates per 1000 p-y, stratified by sex and age (10-year increments) in four cohorts defined by baseline history of diabetes or CHD: no diabetes or CHD (None); prior CHD alone (CHD); diabetes alone (DM); diabetes and CHD (DM+CHD) $A$ Women, $B$ Men

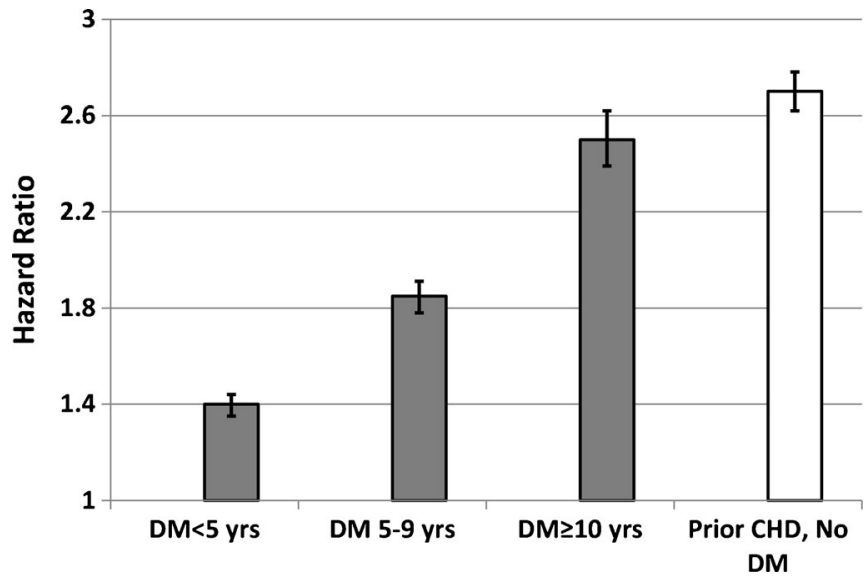

Figure 3 Risk of CHD by duration of diabetes versus prior CHD. CHD risk among individuals with diabetes alone (DM) by duration of diabetes, versus prior coronary heart disease alone (CHD). Hazard ratios adjusted for same variables as in fully adjusted model 5 in Table 2. 


\section{DISCUSSION}

This analysis of a contemporary, large, real-world population with uniform access to integrated care suggests that the presence of prior CHD alone was associated with approximately twice the age-adjusted rate of CHD compared to prevalent diabetes alone. Prevalent diabetes alone or CHD alone was associated with approximately double and triple the CHD risk, respectively, when compared to individuals without a history of diabetes or CHD. In general, prior CHD was not CHD riskequivalent to having diabetes alone, except among individuals with a long duration of diabetes ( $\geq 10$ years).

Our study findings confirm the approximately twofold excess risk of CHD due to the presence of diabetes, as reported previously in a meta-analysis by the Emerging Risk Factors Collaboration. ${ }^{19}$ However, our study suggests that having diabetes does not unconditionally translate into CHD risk equivalence. Almost 17 years ago, Haffner et al. reported findings from a study of 2432 Finnish subjects demonstrating that those with diabetes without prior MI had a risk of MI that was as high as that of patients without diabetes with a history of $\mathrm{MI}^{2}{ }^{2}$ This led to the concept of diabetes as a CHD risk equivalent, which has been challenged and remains controversial. ${ }^{5,6}$ A meta-analysis of 13 studies including 19,072 individuals with diabetes noted that individuals with diabetes alone had a $43 \%$ lower risk of developing CHD than those with prior CHD but without diabetes. ${ }^{5}$ Our data also demonstrate that individuals with prevalent diabetes alone had substantially lower risk (adjusted HR 0.61; $95 \%$ CI, 0.60-0.63) of developing CHD than those without diabetes and with prior CHD. Our study confirms in a real-world population the findings of the previous meta-analysis based on more controlled epidemiologic cohorts. The present study is also unique in having no limitations associated with the meta-analysis, including heterogeneous population, lack of access to individual patient data, and inability to adjust for differences in age, sex and confounders across the studies. ${ }^{5}$ Furthermore, only a limited number of studies had data for both men and women. ${ }^{5}$ Finally, our single study with a diabetes population of 138,507 individuals is several-fold larger than all the studies in that analysis combined.

A large Danish study, ${ }^{13}$ not included in the abovementioned meta-analysis, compared 71,801 individuals with diabetes and 3,202,671 without diabetes. The authors concluded that the risk of the composite endpoint of MI, stroke, and CVD death among patients with diabetes was similar to those with prior MI. However, for the outcome of CHD, this Danish study showed patterns similar to those of the meta-analysis and of our present study. Of note, that analysis was less contemporary (1997-2002), limited by a shorter (5-year) follow up, and lacked data to adjust for confounders such as smoking and hypertension.

Other studies have further stratified by duration of diabetes in order to identify a particular subset of individuals with diabetes that fits the concept of $\mathrm{CHD}$ risk equivalent. $\mathrm{Hu}$ et al. examined the impact of diabetes and history of CHD on fatal CHD among women aged 30 to 55 years in the Nurses' Health Study over a 20 - year follow-up (1976 to 1996). ${ }^{7}$ They reported that women with prior CHD alone had a relative risk (RR) of 8.61 (95\% CI, 7.08-10.5), which was similar to that among women with diabetes for more than 15 years (RR 8.66; $95 \%$ CI, 6.87-10.9). In a more recent analysis of a 9-year follow-up of older men aged 60 to 79 years from the British Regional Heart Study, the authors reported that a threshold for diabetes duration of 8 years was required for diabetes to be regarded as risk equivalent. ${ }^{8,20}$ Like the British Regional Heart Study, we found that long duration ( $\geq 10$ years) of diabetes was "CHD risk equivalent".

Our study had the ability to explore the heterogeneity in CHD risk in both men and women, and across a very wide age range of 30 to 90 years (Fig. 2). While these rates are far less than reported previously in observational studies, they are consistent with contemporary findings from the Multi-Ethnic Study of Atherosclerosis (MESA) cohort study. Malik et al. ${ }^{21}$ reported that the unadjusted CHD rate for 45-84-year-old MESA participants with diabetes $(n=881)$ was $15.2 / 1,000$ py $(1.5 \%$ annually). Our study shows that CHD rates were extremely low among 30-40-year-old subjects with diabetes alone (annual CHD rates $0.5 \%$ and $0.3 \%$ for men and women, respectively). Based on a recent examination of the 2013 ACC/AHA Pooled Cohort Equation, the inclusion of diabetes in the scoring criteria rather than considering diabetes as an automatic CHD equivalent led to important differences in predicted risk that might influence decision-making in younger patients with diabetes. ${ }^{22}$ Our findings differ substantively from the influential findings in the original Haffner et al. ${ }^{2}$ paper, possibly due to the last decade's greatly intensified primary prevention efforts to reduce the risk for CHD in individuals with diabetes. Furthermore, they lend support for the 2013 ACC/AHA risk assessment guidelines' inclusion of diabetes as a predictor rather than an automatic CHD risk equivalent.

\section{Study Limitations}

Our study had several noteworthy weaknesses and strengths. We did not validate the method of CHD ascertainment, which was based on electronic medical records data. However, previously published chart review validations support the use of ICD-9-based ascertainment derived from Kaiser electronic medical records data. ${ }^{16}$ These studies have been published for wide variety of epidemiologic and health services research and have demonstrated face validity. ${ }^{16,23-25}$ Most importantly, while no single form of ascertainment is without error, differential ascertainment across the four exposures groups (no CHD or DM, prior CHD alone, existing DM alone, both $\mathrm{DM}$ and prior $\mathrm{CHD}$ ) that would bias our comparison of these exposure groups in a substantive manner is highly unlikely. Our study could not account for lifetime risk associated with the presence of diabetes. Selective differential enrollment or dis-enrollment of persons by health status over time could bias our estimates of the CHD rates. We censored patients (i.e., 
they no longer contributed person-time) when there was loss to follow-up in our time-to-event analysis. Another limitation of these real-world data is that we may have missed important variables (e.g., body mass index, biomarkers, or physical activity), usually available for clinical epidemiologic study cohorts or randomized controlled trials, that potentially differed across exposure groups (i.e., residual confounding). Finally, our study population was all insured patients receiving integrated medical care in the KPNC healthcare delivery system and exposed to population-based interventions. Thus our results may not be fully generalizable to other health care settings. ${ }^{24,25}$ Strengths of our study include the large sample size $(n=1,586,061)$, long follow-up (median of 10 years), representation of all major races/ethnicities, both genders, and inclusion of a wide age range, and the extensive capture of endpoints and confounding data facilitated by a state-of-theart electronic medical record.

In conclusion, diabetes alone did not confer risk of CHD equivalent to that of individuals with prior CHD in this large, contemporary real-world population receiving integrated care. Compared to individuals without prevalent diabetes or CHD, the risk doubled among those with diabetes alone, but tripled among those with prior CHD alone. However, prevalent diabetes of longer ( $\geq 10$ years) duration conferred a risk of CHD equivalent to those with prevalent CHD. CHD event rates were very low among individuals with diabetes who were less than 40 years of age. These observational data are not sufficient to recommend modifications in any treatment recommendations, but they are important for informing expectations of the natural history of these two chronic conditions.

Corresponding Author: Jamal S. Rana, MD, PhD; Division of CardiologyKaiser Permanente Oakland Medical Center, Oakland, CA, USA (e-mail:jamal.s.rana@kp.org).

\section{Compliance with Ethical Standards:}

Funding Sources: This study was supported by a grant from the Kaiser Permanente Northern California Community Benefit Program.

Conflict of Interest: The authors declare no conflicts of interest.

\section{REFERENCES}

1. American Diabetes Association. Economic costs of diabetes in the U.S. in 2012. Diabetes Care. 2012;36:1033-46.

2. Haffner SM, Lehto S, Ronnemaa T, Pyorala K, Laakso M. Mortality from coronary heart disease in subjects with type 2 diabetes and in nondiabetic subjects with and without prior myocardial infarction. N Engl J Med. 1998;339:229-234.

3. Executive summary of the third report of the national cholesterol education program (NCEP) Expert panel on detection, evaluation, and treatment of high blood cholesterol in adults (adult treatment panel III). JAMA 2001; 285: 2486-97.

4. Goff DC Jr, Lloyd-Jones DM, Bennett G, Coady S, D'Agostino RB Sr, Gibbons R, Greenland P, Lackland DT, Levy D, O'Donnell CJ, Robinson JG, Schwartz JS, Shero ST, Smith SC Jr, Sorlie P, Stone NJ, Wilson PW,
American College of Cardiology/American Heart Association Task Force on Practice Guidelines. ACC/AHA guideline on the assessment of cardiovascular risk: a report of the American college of cardiology/ American heart association task force on practice guidelines. J Am Coll Cardiol. 2014;63(25 Pt B):2935-2959.

5. Bulugahapitiya U, Siyambalapitiya S, Sithole J, Idris I. Is diabetes a coronary risk equivalent? systematic review and meta-analysis. Diabet Med. 2009;26:142-148.

6. Wong ND. Is diabetes really a coronary heart disease risk equivalent? Cardiovasc Endocrinol. 2012;1:65-67.

7. Hu FB, Stampfer MJ, Solomon CG, et al. The impact of diabetes mellitus on mortality from all causes and coronary heart disease in women: 20 years of follow-up. Arch Intern Med. 2001;161:1717-1723.

8. Wannamethee SG, Shaper AG, Whincup PH, Lennon L, Sattar N. Impact of diabetes on cardiovascular disease risk and all-cause mortality in older men: influence of age at onset, diabetes duration, and established and novel risk factors. Arch Intern Med. 2011;171:404-410.

9. Daniels LB, Grady D, Mosca L, Collins P, et al. Raloxifene Use for the Heart (RUTH) Trial Investigators. Is diabetes mellitus a heart disease equivalent in women? Results from an international study of postmenopausal women in the Raloxifene Use for the Heart (RUTH) Trial. Circ Cardiovasc Qual Outcomes. 2013;6:164-170.

10. Lotufo PA, Gaziano JM, Chae CU, Ajani UA, Moreno-John G, Buring JE, Manson JE. Diabetes and all-cause and coronary heart disease mortality among US male physicians. Arch Intern Med. 2001;161:242-247.

11. Wannamethee SG, Shaper AG, Lennon L. Cardiovascular disease incidence and mortality in older men with diabetes and in men with coronary heart disease. Heart. 2004;90:1398-1403.

12. Pajunen $\mathbf{P}$, Koukkunen $\mathbf{H}$, Ketonen $\mathbf{M}$, et al. Myocardial infarction in diabetic and non-diabetic persons with and without prior myocardial infarction: the FINAMI Study. Diabetologia. 2005;48:2519-2524.

13. Schramm TK, Gislason GH, Køber L, et al. Diabetes patients requiring glucose-lowering therapy and nondiabetics with a prior myocardial infarction carry the same cardiovascular risk: a population study of 3.3 million people. Circulation. 2008;117:1945-1954.

14. Huang ES, Laiteerapoing N, Liu J, John PM, Moffet HH, Karter AJ. Rates of complications and mortality in older diabetes patients: the diabetes and aging study. JAMA Intern Med. 2014;174:251-258.

15. Krieger N. Overcoming the absence of socioeconomic data in medical records validation and application of a census based methodology. Am J Public Health. 1992;82:703-710.

16. Yeh RW, Sidney S, Chandra M, Sorel M, Selby JV, Go AS. Population trends in the incidence and outcomes of acute myocardial infarction. N Engl J Med. 2010;362:2155-2165.

17. Karter AJ, Schillinger D, Adams AS, et al. Elevated rates of diabetes in pacific islanders and Asian subgroups: the diabetes study of northern California (DISTANCE). Diabetes Care. 2013;36:574-579.

18. Karter AJ, Nundy S, Parker MM, Moffet HH, Huang ES. Incidence of remission in adults with type 2 diabetes: the diabetes \& aging study. Diabetes Care. 2014;37:3188-3195.

19. Emerging Risk Factors Collaboration, Sarwar N, Gao P, Seshasai SR, et al. Diabetes mellitus, fasting blood glucose concentration, and risk of vascular disease: a collaborative meta-analysis of 102 prospective studies. Lancet. 2010;375:2215-2222.

20. Idris I. Diabetes and cardiovascular risk equivalency: do age at diagnosis and disease duration affect risk stratification?: comment on "impact of diabetes on cardiovascular disease risk and all-cause mortality in older men". Arch Intern Med. 2011;171:410-411.

21. Malik S, Budoff MJ, Katz R, et al. Impact of subclinical atherosclerosis on cardiovascular disease events in individuals with metabolic syndrome and diabetes: the multi-ethnic study of atherosclerosis. Diabetes Care. 2011;34:2285-2290.

22. Karmali KN, Goff DC Jr, Ning H, Lloyd-Jones DM. A systematic examination of the 2013 ACC/AHA pooled cohort risk assessment tool for atherosclerotic cardiovascular disease. J Am Coll Cardiol. 2014;64:959-968.

23. Chang TI, Leong TK, Boothroyd DB, Hlatky MA, Go AS. Acute kidney injury after CABG versus PCI: an observational study using 2 cohorts. J Am Coll Cardiol. 2014;64:985-994.

24. Karter AJ, Ferrara A, Liu JY, Moffet HH, Ackerson LM, Selby JV. Ethnic disparities in diabetic complications in an insured population. JAMA. 2002;287:2519-2527.

25. Jaffe MG, Lee GA, Young JD, Sidney S, Go AS. Improved blood pressure control associated with a large-scale hypertension program. JAMA. 2013;310:699-705. 